\title{
A modernização do sistema educacional na França: a Nova Gestão Pública entre a afirmação do Estado e o governo descentralizado ${ }^{1}$
}

\author{
The modernization of the educational system in France: the New Public \\ Management between the affirmation of the State and the decentralized \\ government \\ La modernización del sistema educativo en Francia: la Nueva Gestión Pública \\ entre la afirmación del Estado y el gobierno descentralizado
}

JEAN-LOUIS DEROUET

\begin{abstract}
Resumo: O texto examina o processo de modernização do Sistema Educacional na França, buscando compreender a afirmação do Estado e o governo descentralizado no contexto de discussão da Nova Gestão Pública. Examinamse os legados, narrativas e políticas de modernização, bem como os paradoxos da nova administração pública francesa na educação. Questiona-se se a Nova Gestão Pública foi, de fato, implementada no sistema educacional francês. Afirma-se que, na educação, apenas a responsabilidade administrativa e financeira adentrou nas instituições sem ter acarretado muitas consequências no trabalho dos professores. Os principais professores e fiscais estão desenvolvendo avaliações e auditorias, e assinando contratos, mas a estrutura burocrática predomina. Entende-se, todavia, que vem sendo buscada uma terceira via entre o Estado e o mercado, especialmente no tocante à descentralização, com ênfase nas responsabilidades locais mais compartilhadas e na possível mudança do estatuto dos funcionários públicos.
\end{abstract}

Palavras-chave: modernização; sistema educacional francês; descentralização.

Abstract: This text examines the process of modernization of the Educational System in France. It aims to understand the affirmation of the State and the decentralized government in the context of the discussion of the New Public Management. It examines the legacies, narratives, and policies of modernization, as well as the paradoxes of the new French public administration in education. It is questioned if the New Public Management was, in fact, implemented in the French educational system. It is stated that, in education, only administrative and financial responsibility entered the institutions without making many consequences on the work of teachers. The main teachers and supervisors are signing contracts and developing evaluations and audits, but the bureaucratic

1 Tradução de Luísa de Assis Vieira, graduada em Letras/Inglês (UFG). E-mail: luisadeassisvieira@ gmail.com 
structure still prevails. It is understood, however, that a third way, between the State and the market, is being sought, especially regarding decentralization, with the emphasis on the most shared local responsibilities and the possible changes in the status of civil servants.

Keywords: New Public Management; educational system in France; decentralized government.

Resumen: El texto examina el proceso de modernización del Sistema Educativo en Francia, buscando comprender la afirmación del Estado y el gobierno descentralizado en el contexto de discusión de la Nueva Gestión Pública. Se examinan los legados, narrativas y políticas de modernización, así como las paradojas de la nueva administración pública francesa en la educación. Se ccuestiona si la Nueva Gestión Pública fue, de hecho, implementada en el sistema educativo francés. Se afirma que, en la educación, solo la responsabilidad administrativa y financiera adentró en las instituciones sin haber llevado a muchas consecuencias en el trabajo de los profesores. Los principales profesores y fiscales están desarrollando evaluaciones y auditorías, y firmando contractos, pero la estructura burocrática predomina. Se entiende, todavía, que está siendo buscada una tercera vía entre el Estado y el mercado, especialmente en lo que se refiere a la descentralización, con énfasis en las responsabilidades locales más compartidas y en el posible cambio del estatuto de los funcionarios públicos.

Palabras clave: modernización; sistema educativo francés; descentralización.

\section{INTRODUÇÃO}

A administração da educação francesa orgulha-se de suas tradições que remontam ao Iluminismo e estabilizadas pelo Império Napoleônico. Muitos planos educacionais foram publicados durante a segunda parte do século XVIII, afirmando o seguinte princípio: a educação é de responsabilidade do Estado; não diz respeito a famílias, comunidades e muito menos às congregações religiosas. Isso levou a uma grande desconfiança local, que foi reforçada pelo planejamento do Estado na década de 1960. Este último definiu uma área de captação escolar para o registro de alunos de acordo com a localização de sua casa. A mesma estatística diz respeito à definição de um currículo centrado nas disciplinas acadêmicas e no acesso ao universalismo. Esta tradição republicana francesa é realizada por importantes órgãos profissionais, como a Inspection Générale ou incorporada no Agrégation (um exame especial de seleção para se tornar professor de alto nível no ensino secundário francês). Também penetrou na cultura da profissão docente e no poder de compensação dos sindicatos. Todos os projetos de modernização da escola foram ajustados e adaptados a este quadro. É o caso das escolas francesas, mas também para a implementação da Nova Gestão Pública. 
O sistema educacional também é de grande alcance público. O sistema privado, católico em sua grande maioria, inscreve cerca de 17\% dos alunos. Desde a separação da Igreja e do Estado (1905), esta educação privada já não foi subsidiada. No entanto, no início do regime político da V República, a Lei de Debré estabeleceu um compromisso (1959): uma educação privada e contratada é subsidiada, mas deve respeitar os regulamentos estaduais através do ensino do mesmo currículo, sendo inspecionado e dando o mesmo treinamento para professores.

Desde meados dos anos 1970 até a década de 1980, o sistema escolar abrangente francês foi implementado por governos de direita e de esquerda. Esta política foi uma promessa de democratização para muitos educadores e pais, mas não cumpriu suas expectativas e esperanças (Derouet, 1992). Isso levou a uma crise de confiança no sistema escolar, enquanto alguns intelectuais da esquerda e da direita denunciaram a "falsa democratização" no ensino secundário, que levou, para alguns deles, à "derrota da reflexão". Também foi desafiado por reivindicações para o reconhecimento das diferenças étnicas e religiosas afirmadas nos últimos anos do século XX (Honneth 2000; Fraser 2013). A desconfiança da tradição republicana francesa em relação às comunidades e ao multiculturalismo continua a ser um obstáculo para compreender de forma intelectual o problema. Num período em que a União Europeia põe em evidência a inclusão social das minorias, algumas partes da sociedade francesa são tentadas por um retorno a definições mais tradicionais da República e do secularismo. Esses legados serão descritos na primeira parte deste capítulo.

O clima pessimista em relação ao fracasso do sistema escolar abrangente facilitou a introdução de algumas recomendações relacionadas à responsabilidade das organizações internacionais (Éducation et Sociétés-29, 2012). No entanto, a esquerda e a direita permanecem hostis às ideias de mercado na educação. Eles também têm dúvidas sobre gerenciamento e gerencialismo. Tradicionalmente, a esquerda é anexada ao serviço civil e desconfia dos discursos empresariais e gerenciais. No entanto, há uma outra esquerda que está promovendo algumas ideais novas de governo, descentralização, democracia local e menos intervenção do Estado. Mas isso não levou os responsáveis políticos franceses a se converterem ao liberalismo e às políticas de livre mercado: alguns deles apenas reagem contra o Estado burocrático e reivindicam mais eficiência e qualidade. No geral, o sistema educacional francês incluiu alguns princípios da Nova Gestão Pública em sua tradição burocrática (Bezès, 2009).

Todas estas questões referem-se a diferentes valores e agendas políticas nacionais e internacionais entrelaçadas. Portanto, é difícil caracterizar legados e mudanças nos últimos cinquenta anos. No entanto, é possível fornecer a seguinte 
análise sobre a introdução da Nova Gestão Pública na administração francesa: um período de abertura relativa desde o início dos anos 1980. Foi marcado pela lei geral sobre descentralização, votada em 1981 e por uma nova definição de justiça importada de exemplos britânicos (Derouet et Derouet-Besson, 2008). Este movimento está na raiz das Áreas Prioritárias de Educação e das políticas de autonomia escolar. A primeira conferência de Lisboa (2000) amplificou o movimento, instigando a França para ter em conta as principais recomendações europeias. A primeira medida vinculada a esta nova direção foi a Lei Institucional relativa às Leis Financeiras, aprovada por unanimidade pelo Parlamento em 2001, e que propôs uma nova organização de serviços públicos com base na prestação de contas. A direção proposta é uma estrutura de habilidades básicas que substituiu a estruturação do currículo em disciplinas (Ato de 2005). Esta concepção está longe da tradição francesa e seu impacto real entre os praticantes pode ser questionado, mas agora as habilidades básicas fazem parte da cultura profissional e política. Em comparação, os últimos anos deram a impressão de um fechamento da identidade nacional. A concepção tradicional da República está ameaçada e o partido socialista governante voltou aos seus princípios fundamentais: serviço público, centralização e secularismo (Lawn \& Normand, 2014).

$\mathrm{Na}$ França, não há regulação pelo mercado, nenhum negócio e nenhum sistema de responsabilização de alto risco. Os dados são fornecidos pelo Ministério da Educação para comparar os resultados dos alunos, mas eles são usados para medir a desigualdade de oportunidades e não o desempenho de professores e alunos. A ideia de desempenho é mediada por um aparato burocrático ligado à reforma do Estado além da educação. As palavras de "gestão" e "gerentes" (Clarke \& Newman, 1997) não se encaixam na representação dos executivos, que consideram principalmente que são funcionários públicos respeitando e aplicando regulamentos do Estado. A LOLF propõe uma reestruturação geral dos serviços públicos, mas tem mais impacto nos procedimentos de contabilidade do que nos atores e escolas. Os indicadores da LOLF orientam a ação dos diretores e inspetores, mas não influenciam as condições de ensino e aprendizagem que deixam uma grande autonomia profissional para professores. No entanto, uma responsabilidade branda é gerada pelas mudanças nas missões dos órgãos de inspeção que desenvolvem mais procedimentos de auditoria e auto avaliação, mas permanecem de caráter experimental e não estatutário.

O sistema educacional francês é inserido em um regime pós-burocrático, tendo implementado os seus primeiros padrões em currículo, alfabetização e aritmética. Mas a ideia de que as escolas podem fazer diferença é limitada a questões sobre o ambiente escolar considerado como um meio de lutar contra violência, evasão escolar e exclusão social. Não há propostas sobre como vincular 
currículo, avaliação e desempenho. A gestão pública francesa é uma mistura de modernização e valores conservadores herdados do legado do sistema escolar da República: neutralidade do Estado, igualdade de oportunidades, cidadania comum. Ele mantém sua tradição de padronização centralizada e é cego ao reconhecimento de diferenças e particularidades locais. Ele dá uma influência poderosa aos órgãos profissionais e sindicatos na cimeira do Estado, enquanto a nova reforma da Gestão Pública permanece de cima para baixo e processa vagamente. Até mesmo a reforma da descentralização e o desenvolvimento das avaliações nacionais iniciadas nos anos de 1980 a 1990 tem diminuído durante a última década. A Nova Gestão Pública na França é caracterizada por um conjunto de paradoxos que são explicados ao longo deste capítulo. É um caso singular na paisagem europeia das reformas do MNP e deve ser considerado assim. Também é necessário explicar alguns legados e narrativas que caracterizam esta situação particular.

\section{LEGADOS, NARRATIVAS E POLÍTICAS DE MODERNIZAÇÃO}

As últimas décadas viram uma intensa atividade legislativa. A Lei de Modernização Escolar de 1975 criou o sistema escolar abrangente (collège unique). A noção de um "plano de desenvolvimento escolar" foi consagrada pelo Ato de 1989, que continua a ser a espinha dorsal do regulamento do novo sistema educacional. Este ato é uma lei abrangente que define os princípios fundamentais, mas dá certa autonomia a nível local. No entanto, este tipo de compromisso, inspirado na educação progressiva e "colocando o aluno no centro do sistema educacional", não foi muito compreendido e até mesmo foi recusado pela grande maioria da comunidade educativa para quem a transmissão do conhecimento, o ensino e a deficiência no aprendizado, têm que ser a principal preocupação do sistema escolar. No final, a sociedade em geral não foi apenas decepcionada com os baixos desempenhos das escolas abrangentes na redução das desigualdades, como também se preocupou com o efeito da escolaridade extensiva: o sistema escolar não provocou o avanço social esperado. Mas também houve desilusão em relação à conquista de alunos. As primeiras publicações de pesquisas internacionais não foram tranquilizadoras e o vínculo republicano entre escola e sociedade estava quebrado.

Além dessas incertezas da sociedade francesa, a Conferência de Lisboa (2000) introduziu alguns elementos que foram implementados nos objetivos da Lei de 2005. A Direita introduziu um quadro de competências básicas inspirado no Quadro Europeu de Competências Fundamentais, definido pela Comissão Europeia de Aprendizagem ao Longo da Vida. Quando a Esquerda chegou ao 
poder em 2012, promulgou uma Lei para a Re-fundação do Sistema Escolar. Este título expressa o sentimento de perda de direção na sociedade francesa em relação à sua educação e à vontade de retornar à tradição neo-kantiana dos fundadores da escola republicana no início da década de 1880. A paixão secularista, que se desvaneceu com o declínio da Igreja Católica, recuperou o poder diante do fundamentalismo islâmico (Éducation et Sociétés-33 2014).

Esta atividade legislativa foi apoiada pela criação de ferramentas políticas responsáveis pela sua implementação (Normand \& Derouet, 2016).

\section{A DESCENTRALIZAÇÃO E A AUTONOMIA DAS ESCOLAS}

A tentativa de descentralização seguiu uma reflexão após o movimento de 1968 sobre a possibilidade das escolas se tornarem uma unidade de gestão escolar, enquanto o sistema escolar centralizado, com seus milhões de servidores públicos, foi frequentemente comparado ao Exército Vermelho. No início da década de 1970, um número significativo de medidas foi experimentado, mas a Lei de 1975 encerrou essa mudança e a França retornou à tradição do planejamento estadual. A França implementou o sistema escolar abrangente mais tarde do que outros países da Organização para a Cooperação e Desenvolvimento Econômico. A noção de autonomia escolar, que havia sido conceituada a partir de uma perspectiva pedagógica, teve um significado gerencial. Essa nova ideia de um plano de desenvolvimento escolar foi introduzida em 1982 como um experimento durante a reforma das escolas de ensino médio. Em 1984, um decreto na Lei geral de descentralização conferia a cada escola secundária o status de Escola Pública Local com a possibilidade de o Conselho definir seu plano de desenvolvimento escolar. A esquerda acrescentou um objetivo social: adaptar os métodos de ensino às necessidades dos alunos para evitar desigualdades escolares. No entanto, uma certa visão gerencial ainda permanece e foi inspirada pelas ideias do sociólogo Michel Crozier. O título de um de seus livros resume seus pensamentos: "Modern State, Earnest State” (1986).

Enquanto a noção de um plano de desenvolvimento escolar foi estendida por todo o sistema educacional, o Ato de 1989 tornou-se o pilar dos novos regulamentos. Propôs estabelecer uma série de contratos individuais e morais entre o aluno, a escola e sua família sem renunciar ao conceito de área de captação da escola. No entanto, a lei introduziu algumas possibilidades de escolhas escolares limitadas e emolduradas para famílias que não aceitaram o projeto escolar. Foi o reconhecimento dos direitos das famílias sem se mudar para um sistema baseado 
no mercado. Outra limitação dessa autonomia foi o currículo nacional "intocável”. A autonomia foi, portanto, rapidamente limitada a uma gestão local e estreita, sem meios flexíveis para atingir os objetivos nacionais.

O Ato de 2005 tentou reviver o princípio da autonomia escolar através de uma concepção liberal cautelosa. A principal medida foi a criação de um "conselho pedagógico": os sindicatos se recusaram a permitir que questões sobre o ensino fossem discutidas no nível do conselho de administração, já que muitos membros do conselho não possuem competência nesse campo. Mas o conselho pedagógico, que inclui apenas professores, pode gerenciar o currículo nacional e as condições de ensino local. No entanto, sua implementação tem sido um processo longo e difícil e resultou em efeitos decepcionantes. O Ato de 2005 também abordou as recomendações das organizações internacionais sobre a diversificação do currículo escolar como forma de promover efetividade e equidade. $\mathrm{O}$ artigo 34 da Lei prevê algumas possibilidades de inovação, permitindo que as escolas tenham mais liberdade fora das regulamentações nacionais. Esta medida poderia ajudar algumas escolas a criar uma identidade específica, mas sua escolha e planos de desenvolvimento escolar, com a notável exceção de alguns deles, não eram realmente novos ou criativos. De acordo com a mesma lógica, em 2007, o ministro anunciou mais flexibilidade na política da área de captação da escola e sua abolição foi programada em 2010. Após um grande debate acalorado, foram feitas algumas mudanças neste anúncio. As autoridades locais, que são principalmente contra a escolha de escola, não implementaram essas instruções e continuaram a limitar as possibilidades das famílias que desejavam trabalhar fora do seu escopo. A Esquerda, de volta ao poder, derrubou a política e reforçou a política da área de captação.

\section{O DESENVOLVIMENTTO DA AVALIAÇÃO}

O período é caracterizado pela implementação de um sistema de avaliação. É o resultado de uma longa história. Durante a década de 1970, o antigo sistema de estatísticas administrativas evoluiu para novas missões e objetivos, desenvolvendo um sistema de avaliação. Em 1986, este serviço administrativo tornou-se um diretório pastoral: a Diretoria de Avaliação e Planejamento Direto (Direction de l'Évaluation, de la Prospective et de la Performance - DEPP). Os dirigentes sucessivos compartilharam os mesmos pensamentos sobre profundidade em grande porte, levantamentos de escala e a cultura das estatísticas do Estado. O DEPP teve importantes responsabilidades. Isso assegura "algumas alternativas possíveis" aos que temem que a autonomia da escola levaria a uma perda de controle na direção do sistema educacional. Em resposta às preocupações 
da sociedade sobre a qualidade da aprendizagem, o DEPP também teve a responsabilidade de implementar avaliações periódicas das habilidades dos alunos em diferentes estágios principais do sistema educacional. Todas essas missões foram incorporadas em uma certa concepção da educação política: o objetivo era projetar ferramentas para o Estado através de indicadores construídos a partir de uma perspectiva nacional que levaria em consideração a diversidade de práticas locais (Derouet \& Normand, 2010).

Em nome da sua missão prospectiva, o DEPP apresentou vários convites à pesquisa educacional. O primeiro deles, no final da década de 1980, considerava o retorno do investimento em educação e introduziu, sutilmente, os princípios da responsabilidade francesa. $\mathrm{O}$ retorno sobre o investimento não foi medido apenas através do desempenho, mas pela redução das desigualdades de oportunidade. A segunda missão diz respeito ao investimento educacional das famílias. Esta chamada foi no fluxo do surgimento de um movimento de consumidores escolares e novas opções de escolas privadas. Este último destacou a realidade e a importância da violência escolar. Todos os resultados da pesquisa dos projetos selecionados foram apresentados em relatórios do DEPP, disseminados e resumidos pela imprensa e pela mídia. Após esse período próspero, as missões do DEPP foram revisadas e reduzidas no final da década de 1990: ganhou muita influência em comparação com outras direções e até mesmo com o próprio ministro e teve que se reintegrar na base. $\mathrm{O}$ debate estava mudando: era normal que a avaliação fosse liderada por um Ministério que projetou e implementou políticas educacionais? Diversas reflexões foram inspiradas por exemplos escandinavos, onde as instituições avaliativas estão sob o controle do Parlamento.

Os formuladores de políticas francesas não estão inteiramente familiarizados com este conceito. Mesmo a palavra "agência" é considerada por eles como muito liberal e eles preferem "conselhos superiores" que mantêm uma forte dependência do Estado. Um Conselho Nacional de Avaliação do Sistema Escolar (CNESCO) foi criado em 2014. Um acadêmico foi nomeado presidente do conselho pelo ministro, mas todos os recursos são fornecidos pelos departamentos do Ministério. Além disso, este novo conselho não aboliu os anteriores: o DEPP continua ativo e a fiscalização ainda é responsável pela avaliação de professores e escolas.

Esta situação pode ser considerada emblemática. Os princípios da Nova Gestão Pública foram afirmados e isso não é puramente retórico. Ele deu lugar a uma importante atividade legislativa e reguladora: a França adotou progressivamente recomendações europeias. Mas, de acordo com uma combinação 
estranha, esses princípios foram incluídos na mentalidade administrativa francesa que reformulou os principais problemas. É por isso que alguns cientistas políticos chamam essa evolução de "dependência do caminho" ou "hibridização das políticas" em um contexto nacional. Este processo limita ou mesmo neutraliza o impacto das recomendações internacionais da OCDE e da Comissão Europeia. Nessa perspectiva, é possível ilustrar os paradoxos desta modernização e examinar como a Nova Gestão Pública foi implementada em diferentes áreas, com alguns exemplos de empréstimos de políticas de outros países e organizações internacionais (Charlier, Croché e Leclercq, 2012).

\section{ALÉM DOS LEGADOS E DO REFORMISMO: OS PARADOXOS DA NOVA ADMINISTRAÇÃO PÚBLICA FRANCESA NA EDUCAÇÃO}

Se o planejamento através da ação do Comitê de Planejamento foi considerado por muito tempo como uma alavanca para conciliar os objetivos de igualdade de oportunidades com o desenvolvimento econômico, a crise econômica e o fracasso de escolas abrangentes forçaram o Estado Educativo a uma mudança de política. No início dos anos 1980, como descrito na primeira parte deste capítulo, a orientação continuou sendo uma grande preocupação para os formuladores de políticas, mas a avaliação aparece como uma nova ferramenta de governo para o sistema educacional. Isso explica o desenvolvimento das primeiras avaliações nacionais e a criação da Direção de Avaliação e Planejamento Direto no Ministério da Educação Nacional.

Após os atos de devolução, a Nova Gestão Pública (NGP) francesa correspondeu a um projeto de modernização da educação, mas, ao contrário de outros países, resistiu fortemente ao mercado e à privatização (Pollitt, 1990; Pollitt \& Bouckaert, 2004). Conforme descrito na primeira parte deste capítulo, o legado republicano é uma explicação inicial: o sistema escolar republicano sempre esteva ansioso para reter interesses privados, enquanto a educação estava sendo progressivamente unificada como serviço público. Assim, a reforma da NGP é um compromisso entre a tradição e a modernização e que suscita inúmeros paradoxos, enquanto que, na década passada, a política educativa francesa tornouse cada vez mais permeável aos efeitos da globalização e da europeização (Hood, 1991; Hood \& Peters, 2004). 


\section{A AVALIAÇÃO LIDANDO COM UMA LÓGICA BUROCRÁTICA}

A criação da Diretoria de Avaliação e Planejamento Antecipado ou DEPP (Direction de l'Évaluation et de la Prospective) é um bom exemplo deste tipo de compromisso francês. Embora tenha sido inspirado pela Unidade de Eficácia Escolar criada no Departamento de Educação do Reino Unido, foi concebida pela primeira vez como um instrumento de planejamento para prever a matrícula de estudantes depois que o ministro socialista Jean-Pierre Chevènement anunciou o objetivo de " $80 \%$ da mesma geração para alcançar o bacharelado em 2000 ". Mas esse foi também o resultado de uma experiência internacional que a França esteve envolvida, junto com os EUA e a OCDE, na concepção da educação em indicadores internacionais. Se a lógica de avaliação adentrou progressivamente no sistema educacional francês, não foi para avaliar sua qualidade e eficácia, pelo menos no início. As avaliações nacionais, como indicadores para as escolas, foram ferramentas destinadas a medir a desigualdade dos resultados dos alunos e foram apresentadas como um meio para reduzir essas desigualdades e democratizar o acesso à educação. Os objetivos do ministério não eram promover a escolha escolar e o mercado, mas lutar contra os rankings brutos publicados pela imprensa, o que impediu uma avaliação justa das características sociais e do mérito de cada escola. Hoje, os testes ainda são formativos e não somativos: eles ajudam professores a melhorar suas práticas de ensino, e não são usados para selecionar os alunos.

Foi apenas durante a década de 1990 que a avaliação começou a ser considerada como uma ferramenta para medir a eficácia e a qualidade do sistema educacional. Entretanto, surgiu um novo paradigma. Claude Thélot, que desempenhou um papel importante como chefe do DEPP, foi o condutor dessa transformação (Thélot, 1993). A avaliação adotou os princípios da Nova Gestão Pública (Economia, Eficiência, Eficácia), enquanto foi criado um Conselho Superior para a Avaliação da Educação (Haut Conseil de l'Évaluation de l'École). Ele rapidamente se tornou um grupo de reflexão para especialistas e formuladores de políticas. Este Conselho Superior publicou relatórios que alegavam alinhar o sistema de avaliação francês com as pesquisas internacionais lideradas pela OCDE, em particular a pesquisa PISA (Henry et al, 2001). O Conselho Superior também promoveu a ideia de um quadro de competências básicas após um inquérito nacional generalizado intitulado "O Grande Debate nas Escolas", com base em dados e questões elaborados pelo DEPP com o apoio de uma empresa de consultoria. A França se integrou mais tarde, pelo Grupo Permanente Europeu sobre Indicadores e Pontos de Referência, para participar na construção 
dos indicadores do Método Aberto de Coordenação. A pesquisa PISA tornou-se progressivamente uma referência para os formuladores de políticas, e a Finlândia é um exemplo de uma reforma bem-sucedida na educação.

$\mathrm{Na}$ França, a educação é um serviço público e de administração estatal (Derouet, 2000). É, portanto, diretamente submetida a reformas promulgadas pelo Estado. Como vimos, a avaliação tornou-se um componente importante na ação do Estado através da promulgação do Ato Institucional relacionado às Leis Financeiras de 2001 (Loi d'Organisation des Lois de Finances ou LOLF). Esta Lei institucionalizou novos regulamentos para a despesa pública através de programas e objetivos nacionais que devem ser avaliados. Portanto, cada administração e cada departamento do Estado deve ser responsável. Mas a prestação de contas na educação continua sendo muito administrativa e financeira e, mesmo que inclua os resultados dos exames dos alunos em seus indicadores, não exerce pressão sobre as escolas quanto ao desempenho, ao contrário da Inglaterra (Mahony \& Hextall, 2000; Gleeson \& Husbands, 2001). Na verdade, nenhum sistema de informação ou ferramenta de avaliação digital foi desenvolvido para tornar os professores mais responsáveis.

O LOLF manteve-se muito burocrático e serviu principalmente para justificar o processo de tomada de decisão para redução de orçamentos e processos de redução de custos com instrumentos brutos, mesmo do ponto de vista gerencial. Na educação, o gerenciamento não compartilha os mesmos valores que os gestores: eles costumam usar a palavra "monitoramento" para evitar um vocabulário de gestão que muitas vezes se qualificam como "neoliberal". Muitos deles não fazem distinções claras entre "controle" e "avaliação", mesmo que as práticas de auditoria nas escolas estejam sendo desenvolvidas atualmente pelos órgãos de fiscalização (Power, 1997).

\section{UMA DESCENTRALIZAÇÃO LIMITADA EM TERMOS DE TRANSFERÊNCIA DE RESPONSABILIDADES}

A descentralização é limitada em sua extensão. Certamente, os primeiros atos de descentralização delegaram poderes importantes às autoridades locais na construção de escolas, renovação e equipamentos. Este último usou essas novas responsabilidades para receber investimentos significativos e algumas operações de prestígio para fins eleitorais. O objetivo era provar que as autoridades locais podem fazer um trabalho melhor em um contexto de investimento reduzido do Estado. Mas, na educação, a descentralização foi interrompida no início da década de 1980. Foi apenas em 1995 que um novo ato transferiu as responsabilidades da formação profissional de jovens do Estado para as autoridades regionais. 
No entanto, essa descentralização foi parcial: o Estado continua a gerir colégios vocacionais e estágios, mesmo que as regiões sejam responsáveis pela regulamentação da formação profissional através de planos quinquenais.

A educação permanece estreitamente estatista e centralizada. O Estado é o responsável por definir o currículo e o volume de horas de ensino, seleção, recrutamento e carreiras de professores e outros funcionários, treinamento inicial e contínuo, controle e inspeção das escolas, orientação e inclusão profissional escolar, diplomas, certificações e reconhecimento de qualificações. Se a descentralização foi implementada no sistema educacional, dando mais autonomia aos diretores (recteurs), eles permanecem muito dependentes das decisões tomadas pelo Ministério da Educação. Nessas regiões, as relações entre o Estado e as autoridades locais podem ser tensas devido a conflitos em relação à partilha de jurisdição ou oposição ideológica. $\mathrm{Na}$ verdade, os setores da educação primária e secundária estão vagamente acoplados a uma perspectiva cultural e institucional, o que não facilita a cooperação e a administração compartilhada. Os contratos baseados em objetivos definem as relações entre o Estado e as autoridades locais, mas também entre as autoridades locais de educação (Rectorats) e as escolas. Algumas redes de escolas emergem, em particular, para superar a grande divisão entre os setores da educação primária e secundária e desenvolver a cooperação em torno da implementação do quadro de habilidades básicas (veja abaixo).

Uma fonte de debate acalorado é a transferência de funcionários públicos para as autoridades locais que foi realizado com os funcionários e técnicos das escolas. Algumas tentativas semelhantes foram feitas aos membros do conselho escolar. Mas isso falhou devido a protestos em grande escala pelo corpo profissional de Conselheiros e Psicólogos de Orientação Escolar (Conseils d'Orientation Psychologues), que se opôs ideologicamente a um conceito de aconselhamento defendido pelas autoridades locais através de uma forte cooperação com empresas e serviços regionais envolvidos na avaliação de habilidades ou integração profissional. O aconselhamento também tem influência poderosa no Ministério da Educação e atua como uma espécie de lobista interno. Especialistas e formuladores de políticas estão atualmente pensando na criação de um serviço de aconselhamento público regional, mas nada de concreto foi proposto pelo ministério até agora.

\section{A RETENÇÃO DE UMA TRADIÇÃO CULTURAL, APESAR DE UMA POLÍTICA DE HABILIDADES BÁSICAS}

O Quadro de Competências e Conhecimentos Básicos (Socle Commun de Connaissances et de Compétences) é a obra-prima da Lei Escolar de 2005, votada 
durante o exercício do ministro François Fillon. Ele deu origem a um conjunto de narrativas (podemos até dizer histórias narradas) que o descreveu como o legado dos sucessivos planos educacionais a partir da fundação do Sistema Escolar Republicano. Mas este quadro é uma tradução, como vimos, com algumas pequenas mudanças, do quadro europeu de competências-chave concebido em 2004 pela Comissão Europeia, enquanto a França esteve envolvida há vários anos na implementação da Estratégia de Lisboa. A política de viagens de habilidades básicas implementada nos EUA e no Reino Unido no início da década de 1980 só retornou, após mais de duas décadas (Ozga \& Jones, 2006).

No entanto, o Quadro Francês de competências-chave está completamente desconectado de questões de avaliação e aprendizado. Ele liderou uma guerra curricular na França através de batalhas ideológicas (Shor, 1986). Em termos curriculares, os modernizadores se opõem aos tradicionalistas. Os primeiros querem adaptar o ensino das disciplinas escolares às necessidades dos estudantes e reivindicar um vínculo mais forte entre os conteúdos a serem transmitidos pelos professores e habilidades a serem adquiridas pelos alunos. Os últimos desejam manter um alto nível de exigência de conteúdo e criticar uma concepção instrumental do currículo que distorce a cultura transmitida aos alunos. É por isso que o atual governo socialista acrescentou a "cultura comum" ao quadro de "habilidades básicas e conhecimento" para satisfazer as reivindicações do principal sindicato de professores. No entanto, essa divisão ultrapassa a oposição tradicional entre a esquerda e a direita.

Nesta perspectiva, a ação do Estado está dividida entre vários requisitos contraditórios. O Estado espera que o quadro de competências básicas seja uma ferramenta de diversificação pedagógica para apoiar a orientação e o desempenho individual dos alunos. Mas, ao mesmo tempo, ele continua a ser anexado a um objetivo de condições de ensino iguais para todos os alunos, e defende uma ideia padronizada do currículo. Além desse paradoxo entre padronização e diversificação, existe uma forte tensão entre avaliação e currículo (Revue Française de Pédagogie, 2011).

Cada professor é considerado autônomo em sua sala de aula e, em nome de sua "liberdade pedagógica", é reconhecido e reafirmado no Código de Educação. Ao mesmo tempo, como funcionários públicos, eles têm que aplicar instruções oficiais promulgadas pelo Ministério para a implementação do currículo (Normand, 2012). No entanto, eles têm um poder arbitrário para avaliar os alunos geralmente através das notas. A falta de um vínculo entre o currículo e as avaliações impede os professores de considerarem a questão das habilidades dos alunos, enquanto eles não se sentem preocupados com a aprendizagem dos estudantes, mas apenas pelo conteúdo de ensino. Isso explica por que o Conselho 
Superior de Currículo (Conseil Supérieur des Programmes) teve que adaptar o currículo ao Quadro de Habilidades Básicas, e recentemente propôs a implementação de uma avaliação sem conceitos aos estudantes de pós-graduação de acordo com seus níveis de dificuldades de aprendizagem, como já foi feito em outros países europeus. Mas, até agora, as recomendações do Conselho Superior não tiveram muito impacto na formulação de políticas.

\section{SELEÇÃO ESCOLAR SEM O DESENVOLVIMENTO DO MERCADO}

A ideologia do mercado serviu à política de desregulamentação das áreas de captação. A Direita, sob o governo de Sarkozy, procurou levantar a questão da escolha escolar, enquanto a Esquerda se opôs fortemente a defender uma diversidade social nas escolas. No entanto, ao contrário da Inglaterra, esta desregulamentação estava ligada a um certo número de requisitos que limitaram sua extensão (Ball, 2008). Em primeiro lugar, houve a questão das vagas limitados nas melhores escolas. Em segundo lugar, a seleção e inscrição dos alunos teve que respeitar critérios rigorosos (irmãos, bolsas, necessidades especiais, etc.) que restringiram o número de casos examinados através de regulamentos burocráticos que restringiam a voz dos pais e sua mobilização. Os principais professores, juntamente com alguns gestores locais, também relutam em implementar essa política. No entanto, como já foi observado em outros lugares, o resultado foi um aumento na segregação social com o desafio das escolas perderem seus melhores alunos, e essa política não compensou a predominância das famílias de classe média e alta nas estratégias escolares. Esse quadro foi bem-sucedido no desenvolvimento de um mercado para as escolas e pelo fortalecimento da concorrência entre as escolas, como é o caso no Reino Unido (Tomlinson 2005; Walford 2006). Esta política foi abandonada pela Esquerda, na sua chegada ao poder em 2012.

Simultaneamente, o forte apego à igualdade de oportunidades levou à concepção e implementação de alguns sistemas que misturam a escolha da escola com os princípios da seleção meritocrática contra os alunos desfavorecidos. É por isso que algumas instituições de ensino superior, seguindo o exemplo de SciencesPo Paris, desenvolveram procedimentos de orientação em escolas com déficits, enquanto as aulas preparatórias para instituições de ensino superior abriram suas portas a alunos que mereciam em prol da discriminação positiva.

Como alguns resultados de pesquisa sociológica demonstram, essa ação permitiu que as instituições de ensino superior exibissem uma política de abertura para silenciar a crítica do seu elitismo excessivo, mantendo uma forte 
seleção em seus exames de admissão. O outro sistema inventado pela Direita foi o dos internatos no modelo Internats d'Excellence, copiando as Escolas Charter dos Estados Unidos. Essas escolas para estudantes de redes privadas, propõem melhor apoio no ensino e na aprendizagem enquanto isolam os alunos do contexto familiar e social para oferecer melhores condições de estudo. No entanto, a gestão parece extremamente heterogênea de uma escola para outra, dependendo do envolvimento das autoridades locais, da mobilização das equipes de ensino, dos procedimentos de recrutamento, do grau de autonomia da estrutura pedagógica, etc. Essas escolas contribuíram para reivindicações de meritocracia imaginária enquanto servem como ferramentas de propaganda na mídia para promover uma discriminação positiva com efeitos limitados no final.

\section{AS FALHAS NA REFORMA CONSERVADORA DA ESQUERDA}

Uma vez que os socialistas chegaram ao poder em 2012, esta política de diversificação e escolha escolar foi interrompida à medida que reivindicavam a vontade de reduzir a desigualdade de oportunidades e fortalecer a combinação escolar. A autonomia escolar, que a Direita queria promover ao dar mais responsabilidade aos diretores, também foi interrompida enquanto uma concepção legitimista voltou a dominar o órgão geral de inspeção. Vincent Peillon, ministro da Educação Nacional, reuniu todos os gestores de alto nível dos distritos de Paris e disse-lhes que "gestão" e "governança" não pertenciam ao seu vocabulário. Em vez disso, foi difundida uma retórica sobre uma nova base do sistema escolar, enquanto os princípios do Sistema Escolar Republicano foram reafirmados particularmente através da implementação do ensino da "moralidade secular" nas escolas. $\mathrm{Na}$ verdade, o ministro tem uma base filosófica e ele permaneceu muito ligado aos valores e princípios republicanos, sendo inspirado pelos fundadores do Sistema Escolar Republicano (Kahn, 2015). Cumprindo seus valores republicanos, esse governo de Esquerda promove o Quadro de Habilidades Básicas como meio de democratização e redução de desigualdades de oportunidades.

A Comissão para a Nova Fundação do Sistema Escolar, criada pelo Ministro para implementar um novo ato não levou a uma reforma substancial, apesar de seus numerosos grupos de trabalho e sua cobertura de mídia. A ideia de concentrar os esforços do sistema educacional no setor de educação primária só adotou algumas recomendações de organizações internacionais. $O$ desenvolvimento de um plano nacional para tecnologias digitais corresponde a objetivos semelhantes sem se envolver profundamente no Ministério, enquanto as instalações dependem principalmente das autoridades locais. Além disso, a reação das autoridades locais explica o fracasso da reforma dos horários escolares 
enquanto foi apresentado como um programa-chave do Ato. Sucumbindo ao lobbying de médicos próximos da Academia das Ciências, o Ministro decidiu implementar um plano nacional para a reestruturação de horários nas escolas primárias depois de ter sido aceito pelos sindicatos.

Uma vez anunciada a reforma, não demorou muito para que os sindicatos negassem o Ministério enquanto professores, autoridades locais e pais manifestavam sua insatisfação com uma reforma mal preparada, mal negociada e subfinanciada. Foi o mesmo para a reforma das Escolas de Pós-Graduação em Educação (ESPE: Écoles supérieures du Professorat de l'Éducation) e da formação inicial de professores. Foi muito rapidamente inserido em uma tormenta burocrática e um ressurgimento de conflitos de interesse. Enquanto isso, o ministro tentou colocar a reforma da profissão docente na agenda política, não teve tempo de implementá-la e seus seguidores não lhe deram apoio suficiente. Eles preferiram concentrar suas ações na reestruturação do currículo nacional de acordo com o quadro básico de habilidades e tentar promover a combinação escolar, transformando a provisão escolar ao particularmente diminuir algumas opções elitistas como Alemão, Latim ou alguns cursos bilíngues que levaram a inúmeros protestos de grupos de interesse e sindicatos baseados em disciplina.

\section{CONCLUSÃO}

A falta de reestruturação da profissão docente, uma autonomia limitada para as escolas, as opções de escolas na periferia, um mercado escolar com consequências restritas, uma ideologia gerencial com oposição significativa, uma descentralização mal sucedida: nessas condições, é difícil dizer que a Nova Gestão Pública foi implementada no sistema educacional francês. Isso contrasta fortemente com o setor da saúde, onde gestão de desempenho, procedimentos de qualidade, flexibilidade e mobilidade, e contratos e agências que criaram uma nova configuração de serviço público nos hospitais. $\mathrm{Na}$ educação, apenas a responsabilidade administrativa e financeira adentrou as instituições no longo prazo sem ter acarretado muitas consequências no trabalho dos professores. Os principais professores e fiscais estão desenvolvendo avaliações e auditorias, e assinando contratos, mas a estrutura burocrática predomina.

No entanto, as reflexões atuais entre especialistas e formuladores de políticas, tanto da Esquerda quanto da Direita, nos levam a pensar que eles estão buscando uma espécie de terceira via entre o Estado e o mercado (Normand, 2016). O terceiro passo na descentralização, na sequência da criação de novas entidades regionais levando a uma reestruturação de como as responsabilidades locais são compartilhadas pode ser o principal objetivo da próxima reforma 
na educação. Outra questão está relacionada com a reforma do estatuto dos funcionários públicos que poderia ter consequências para o serviço público nacional de educação. No entanto, o confronto entre a Esquerda e a Direita em relação a este projeto permanece muito decisivo, e os sindicatos estão prontos para defender ferozmente os seus direitos.

\section{REFERÊNCIAS}

BALL S.J. 2008 The Education Debate, Bristol, The Policy Press

BEZES P. 2009 Réinventer l'État. Les réformes de l'administration française, Paris, PUF

CHARLIER J-É., CROCHE S., LECLERCQ B éd. 2012 Contrôler la qualité dans l'enseignement supérieur, Louvain-la-Neuve, L'Harmattan-Academia

CLARKE J. \& NEWMAN J. 1997) The managerial state: power, politics and ideology in the remaking of social welfare, London, Sage

CROZIER M. 1986 État moderne, État modeste. Stratégies pour un autre changement. Paris. Fayard

DEROUET J.-L. 1992 École et Justice. De l'égalité des chances aux compromis locaux?, Paris, Métailié

DEROUET J.-L. \& DEROUET-BESSON M.-C. 2008 Repenser la justice dans l'éducation et la formation, Genève, Peter Lang

DEROUET J.-L. \& NORMAND R. 2010 "Caesars and Rubicon. The hesitations of French policymakers in identifying a Third Way in education and training", Journal of Educational Administration and History, 43, 97-121

ÉDUCATION ET SOCIETES-29 2012 L'Europe : une mise en ordre cognitive ?, coordonné par Roger Dale et Jean-Louis Derouet, dossier commun avec Globalisation, Societies and Éducation

ÉDUCATION ET SOCIETES-33 2014 Concurrence des discours de vérité, coordonné par Sarah Croché 
FRASER N. 2013 Qu'est ce que la justice sociale? Reconnaissance et redistribution, Paris, La Découverte

GLEESON D. \& HUSBANDS C. ed. 2001 The Performing School. Managing Learning and Teaching in a Performance Culture. London, Routledge Falmer

HENRY M., LINGARD B., RIZVI F. \& TAYLOR S. 2001 The OECD, Globalization, and Education Policy. Oxford, Pergamon-Elsevier

HONNETH A. 2000 La lutte pour la reconnaissance. Paris. Éditions du Cerf

HOOD C. 1991 "A public management for all seasons?" Public administration-69(1), 3-19

HOOD C. \& PETERS G. 2004 "The middle aging of new public management: into the age of paradox?", Journal of public administration research and theory-14(3), pp. 267-282

KAHN P. 2015 “L'enseignement moral et civique : vain projet ou ambition légitime ? Éléments pour un débat', Carrefours de l'éducation-39, 185-202

LAWN M. \& NORMAND R. 2014 Shaping of European education. Interdisciplinary Approaches, London: Routledge

MAHONY P. \& HEXTALL I. 2000 Reconstructing teaching: standards, performance and accountability, London, Routledge

NORMAND R. 2012 “French Educators' Uncertainties and Doubts against Changes influenced by Globalization" in Terri Seddon, Jenny Ozga and John Levin, Globalization and professions, Routledge World Yearbook of Education

NORMAND R. 2016 The changing Epistemic governance of European Education. The fabrication of the Homo Academicus Europeanus ? Dordrecht, Springer

NORMAND R. \& DEROUET J.-L. 2016 dir. A European politics of education: perspectives from sociology, policy studies and politics, Abingdon, UK, Routledge, 2016, XI-221 p. 
OZGA J. \& JONES R. 2006 "Travelling and embedded policy: the case of knowledge transfer", Journal of Education Policy, 21(1), 1-19

POLLITT C. 1990 Managerialism and the Public Services: The AngloAmerican Experience, Oxford, Blackwell

POLlit'T C. \& BOUCKAERT G. 2004 Public Management Reform: A Comparative Analysis [2nd éd.], Oxford, Oxford University Press

POWER M. 1997 The Audit Society, London, Demos

REVUE FRANÇAISE DE PEDAGOGIE-174 2011 "Évaluation, développement professionnel, obligation de résultats", coordonné par Jean-Louis Derouet et Romuald Normand

SHOR I. 1986 Culture wars: school and society in the conservative restoration, 1969-1984, Boston, Routledge \& K. Paul

TOMLINSON S. 2005 Education in a post-Welfare Society [2nd éd.], New York, Open University Press

WALFORD G. 2006 Education and the Labour Government: an Evaluation of Two Term, London, Routledge

JEAN-LOUIS DEROUET é Professor emérito da École Normale Supérieure de Lyon, UMR Triangle, França. E-mail: jean-louis.derouet@inrp.fr

Recebido em outubro de 2017 Aprovado em desembro de 2017 